\title{
Quarter 2 Research Performance Progress Report (RPPR) - DOE Solar Program
}

Michael D McMurtrey, Laura J Carroll, Mark Messner

August 2018

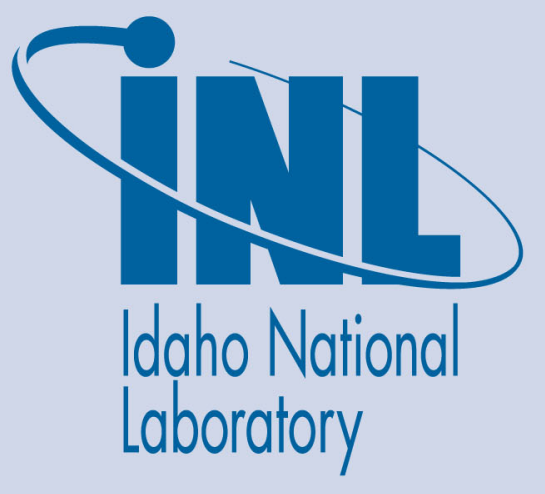

The INL is a U.S. Department of Energy National Laboratory operated by Battelle Energy Alliance 


\title{
Quarter 2 Research Performance Progress Report (RPPR) - DOE Solar Program
}

\author{
Michael D McMurtrey, Laura J Carroll, Mark Messner
}

August 2018

Idaho National Laboratory Idaho Falls, Idaho 83415

http://www.inl.gov

Prepared for the U.S. Department of Energy

Office of Energy Efficiency and Renewable Energy

Under DOE Idaho Operations Office

Contract 33872 


\section{Research Performance Progress Report (RPPR) - DOE Solar Program}

Project Title: $\quad$ Creep-fatigue Behavior and Damage Accumulation of a Candidate Structural Material for Concentrating Solar Power Solar Thermal Receiver

Project Period: $\quad$ 2/01/18 - 1/31/20

Budget Period: $\quad$ 5/01/18 - 7/31/18

Reporting Period: $\quad$ 5/01/18 - 7/31/18

Reporting Frequency: Quarterly

Submission Date: 8/15/18

Recipient: Idaho National Laboratory

Address: 2525 Fremont Ave

Idaho Falls, ID 83402

Website (if available) www.inl.gov

Project Number: $\quad 33872$

Project Team: Idaho National Laboratory

Argonne National Laboratory

Principal Investigator: Michael McMurtrey, Materials Scientist

Phone: (208) 526-2327

Email: michael.mcmurtrey@inl.gov

Business Contact: Gabriel llevbare, Materials Science \& Engineering Manager Phone: 208-526-3735

Email: gabriel.ilevbare@inl.gov

HQ Tech Manager: $\quad$ Mark Lausten

HQ Project Officer: Christine Bing

GO Grant Specialist: GS name

GO Contracting Officer: CO name

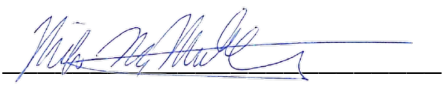




\section{Information from Statement of Project Objectives (SOPO)}

Project Objective: Creep-fatigue deformation is an important consideration for a thermal receiver of a gas phase (GP) Concentrating Solar Power (CSP) system due to the constant static stress or pressure, diurnal cycling, and elevated service temperatures required for efficient operation. An accurate description of the creepfatigue behavior, not available for five of the six candidate materials, is important for assessment of preliminary designs. This project will provide a detailed analysis of the creep-fatigue behavior and damage accumulation of a candidate structural material for a CSP solar thermal receiver to address a critical knowledge barrier for receiver design in the GP pathway concept identified in the CSP Gen3 Demonstration Roadmap. This effort includes the development of rules for the design of solar receiver components against high temperature creep-fatigue and ratcheting failure modes. The ASME Code rules for high temperature nuclear components will form the basis of the method but adjustments will be made to reflect the generally shorter, diurnal operating cycles of thermal receivers and the relative consequences of failure, comparing nuclear to solar components.

\section{Work Planned for this Quarter:}

Task 1, Milestone 1 - Discussion during the Quarter 1 Review, prompted further analysis of the alloy selection, specifically focusing on the comparison of the two materials with the highest temperature creep capability, Alloy $740 \mathrm{H}$ and Alloy 282 . It was recognized that additional analysis would shift the program schedule, particularly with regard to Task 1, Milestone 2 as the material purchase would be on hold until this decision.

Task 1 , Milestone 2 - Initially, plans for this quarter were to progress on-schedule to meet the Quarter 4 milestone of completion of preliminary fatigue and creep-fatigue data. These plans included procuring Alloy $740 \mathrm{H}$ material and machining test specimens for creep and cyclic testing, as well as outlining experimental test matrices to satisfy the ASME design curve requirements. Depending on the timeline for material availability and cyclic machining, initial continuous-cycle fatigue tests were planned for this quarter. Design of the experimental test program in accordance with the applicable ASTM test standards is also planned. The creep and creep-fatigue test matrices will be outlined to satisfy the ASME design curve requirements and an ASME Code expert will provide concurrence or recommended changes.

Task 2 - We continue to evaluate potential creep-fatigue design rules. The primary effort this quarter was on establishing a reference thermomechanical model of a concentrating solar receiver that will be used to evaluate different design approaches. We completed a first version of the receiver model this quarter.

Task 3 - As part of Task 3, we planned to obtain DOE recommendations or concurrence for a shift in project scope from focusing on the influence of environment to investigating the impact of a weld strength reduction factor, weldments, and other material forms (tube, sheet), on the creep-fatigue behavior of Alloy $740 \mathrm{H}$. This is specifically in relation to the creep-fatigue design rules and the potential impact of a 
detriment or benefit of weldments on the creep-fatigue resistance of Alloy $740 \mathrm{H}$. A thorough literature review of similar nickel-base alloys and the potential influence of weldments, weld strength reduction factor, and material product forms on the resulting creep-fatigue behavior was planned. A summary of this review could then form the basis of a recommendation on a path forward. Based on the Quarter 1 review, a discussion on the impact of environment on creep-fatigue testing was also recommended. Again a thorough literature review would serve as the basis for assessing the environmental impact.

\section{Plans for Next Quarter:}

Task 1, Milestone 2 - The plans for next quarter are to progress forward to complete the Quarter 4 milestone. These plans include procuring Alloy $740 \mathrm{H}$ material and machining test specimens for creep and cyclic testing. From machined specimens of currently available Alloy $740 \mathrm{H}$ material, initial creep, fatigue and creep-fatigue tests should be underway this quarter, assuming no delays from the machinist. It is noted that additional fatigue testing will also be necessary from any procured material as it will represent a second heat of material. The experimental test program will be conducted in accordance with applicable ASTM test standards.

Task 2 - We will begin to evaluate different creep-fatigue and ratcheting design methods. This evaluation will include identifying design approaches from the literature, DOE reports, and current Codes and Standards, ranking these approaches on ease of use and availability of design data, and evaluating the design margin inherent in each approach. For the last subtask, because this work will precede the availability of INL test data on Alloy $740 \mathrm{H}$, we will use a reference material that is currently widely available in various design approaches, likely Alloy $800 \mathrm{H}$. To evaluate the design margin in each approach we will use the reference thermomechanical model developed this quarter. For each design approach we will use the model to calculate the design life of the hypothetical receiver under some predefined, realistic insolution history. This will allow us to rank each design approach from most to least conservative. Of course, this is a relative approach and does not address the actual margin in each method, but will enable us to evaluate which methods are most viable for CSP design. We will also consider modifications to the design factors in the different approaches, for example by reducing the strong factors on the fatigue life applied to the ASME Section III, Division 5 procedures for high temperature nuclear reactors to account for the different consequences of failure between nuclear and CSP systems.

Task 3 - Fatigue, creep and creep-fatigue testing procedures and test matrices for sheet material will be developed. As part of this process, a sheet specimen design concurrent with applicable ASTM standards will be developed. Further, discussions with EPRI will be initiated to develop a plan for creep-fatigue and fatigue testing of tubular specimens.

\section{Narrative Report and Update:}

Project Results and Discussion: 
The metric for Task 1, Milestone 1 is the down-selection of a single nickel-base alloy that will be impactful to the Gen3 effort to investigate as part of the project. The high temperatures of an in-service receiver require that the structural material be capable of not only withstanding creep deformation, but also diurnal high temperature cycling [1, 2]. For the CSP technology to meet cost goals, the receiver must meet a lifetime requirement of 30 years or 10,000 cycles [1,2]. Candidate materials for a thermal receiver have been identified [3] and include commercial nickel-base alloys, Alloy 625, INCONEL ${ }^{\circledR}$ alloy $740 \mathrm{H}$ (herein referred to as Alloy $740 \mathrm{H}$ ), Alloy 230 , and Haynes ${ }^{\circledR} 282$ alloy (herein referred to as Alloy 282). After project initiation, it was decided to also consider Alloy 617 and Alloy X. The temperature range of interest was identified as 700 to $850^{\circ} \mathrm{C}$, which enables both gas and salt CSP technologies with an outlet temperature of $750^{\circ} \mathrm{C}$.

During the first quarter, the alloy selection was narrowed down to two candidate alloys, Alloy 282 and Alloy $740 \mathrm{H}$. These alloys were of primary interest based on their high temperature strength and creep resistance at temperatures up to $800^{\circ} \mathrm{C}$. It was further noted that this project will require sufficient creep data for the selected alloy, if not available this data must be generated as part of the project. Creep property data is critical as it is the basis of the creep damage term of the creep-fatigue interaction diagram, or D-diagram. Alloy $740 \mathrm{H}$ does have sufficient creep rupture data available for the D-diagram, as there has been a multi-year DOE Fossil Energy program focused on advanced-ultrasupercritical (A-USC) power plant applications, for which Alloy $740 \mathrm{H}$ is a candidate alloy [3]. A vast amount of creep testing was completed at temperatures up to $850^{\circ} \mathrm{C}[4,5]$ and creep rupture equations are also available [4,5]. While Alloy 282 is also a candidate alloy for A-USC applications, much of the effort focused on creep was directed at determining whether a single step aging treatment resulted in similar properties. It was found that the creep strength at temperatures between 700 and 800 ${ }^{\circ} \mathrm{C}$ of Alloy 282 with a single-step ageing treatment is similar to the material with a twostep aging treatment [4]. So, although there is not an available creep regression equation for Alloy 282, creep data is published [4,6-10], however, much of the data [6$10]$ is for the material with a two-step ageing treatment. Whether there is sufficient creep data with which to develop a creep-fatigue diagram and whether creep data from material with a single-step ageing treatment could be utilized for a D-diagram must be determined.

To make an assessment of the amount of available Alloy 282 creep data and to compare the 700 and $800{ }^{\circ} \mathrm{C}$ creep strength of Alloy 282 and $740 \mathrm{H}$, creep data from multiple sources $[4,8,10]$ were combined and placed on creep rupture plots for 700,750 , and $800{ }^{\circ} \mathrm{C}$, as shown in Figure 1. It is noted that the heat treatments of the material from which both the Alloy 740/740H and Alloy 282 data was generated in Figure 1 varies. The Alloy $740 / 740 \mathrm{H}$ creep data in Figure 1 is from multiple product forms (tube with a $10 \mathrm{~mm}$ wall thickness and $50.8 \mathrm{~mm}$ outer diameter, $75 \mathrm{~mm}$ thick plate, $75 \mathrm{~mm}$ diameter bar, and $15.9 \mathrm{~mm}$ diameter bar) and was annealed and then aged at $800{ }^{\circ} \mathrm{C}$ for 16,8 , or 4 hours [4]. There are minimal Alloy 282 data points at $700^{\circ} \mathrm{C}$ from reference [4] and they are exhibit higher rupture times than the other Alloy 282 data points $[8,10]$. Based on this, it is likely that some confirmatory creep rupture testing of Alloy 282 is necessary at $700{ }^{\circ} \mathrm{C}$. The majority of Alloy 282 data available is at $750{ }^{\circ} \mathrm{C}$ 
and the data from one reference [4] indicates improved strength relative to Alloy $740 / 740 \mathrm{H}$. Similar to at $700{ }^{\circ} \mathrm{C}$, the data from reference [8] is lower and again in line with Alloy $740 / 740 \mathrm{H}$. The third set of Alloy 282 data [10] was generated at $760{ }^{\circ} \mathrm{C}$ so, although included in Figure 1, it must be compared in a LM plot. Only one reference [4] contains data at $800{ }^{\circ} \mathrm{C}$, the data does show an advantage in the Alloy 282 creep strength relative to Alloy $740 / 740 \mathrm{H}$, as shown in Figure 1(c).

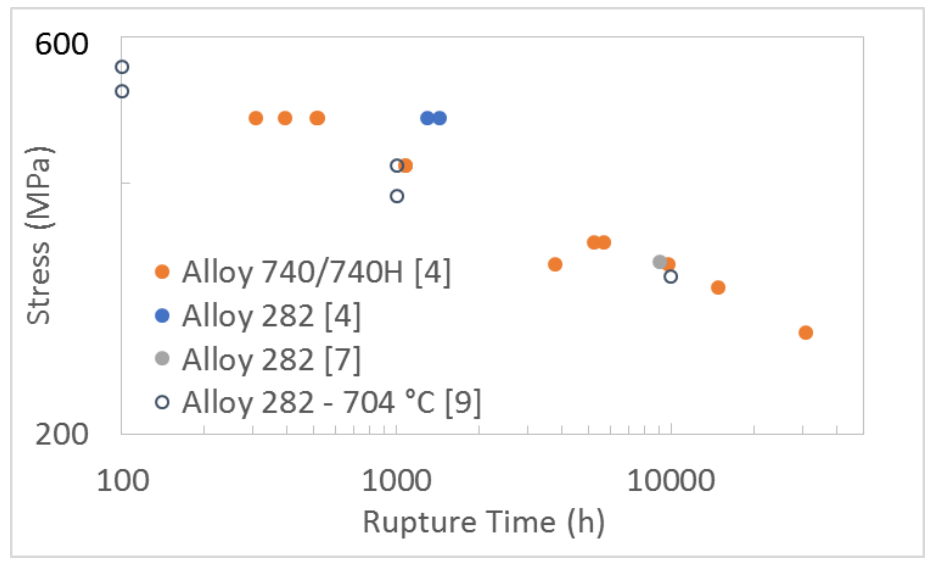

(a)

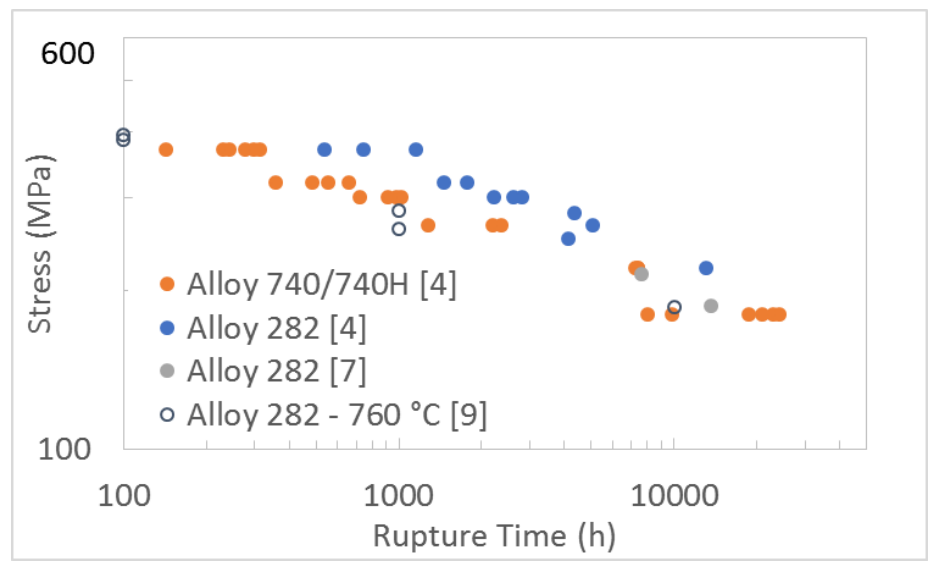

(b)

Page 5 of 24 


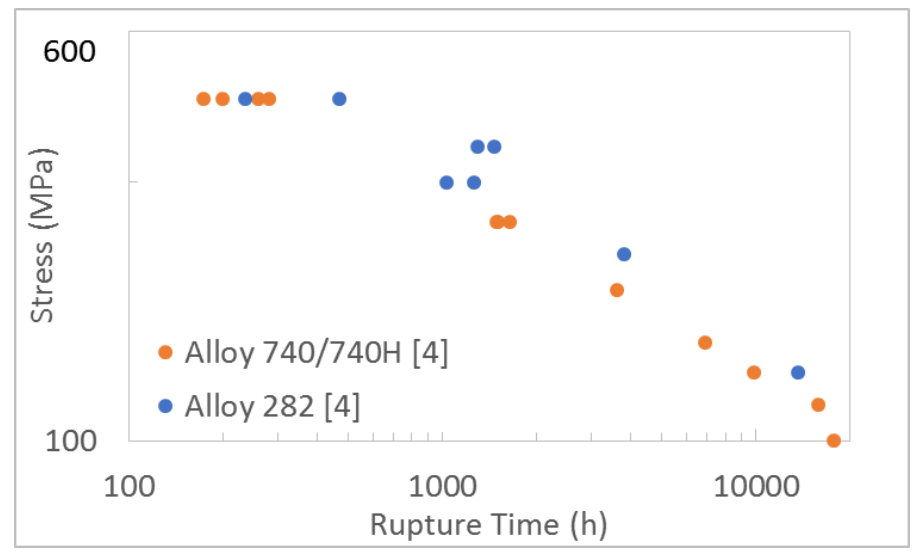

(c)

Figure 1 - Available Alloy $740 / 740 \mathrm{H}$ and Alloy 282 creep rupture data at $700{ }^{\circ} \mathrm{C}(\mathrm{a}), 750$ ${ }^{\circ} \mathrm{C}(\mathrm{b})$, and $800{ }^{\circ} \mathrm{C}$ (c) replotted from data in references [4,8,10] for Alloy 282 and reference [4] for Alloy $740 / 740 \mathrm{H}$. Heat treatments vary within this data set, even for a given alloy.

Additional Alloy 282 data is also available at temperatures of 649,927 , and $982{ }^{\circ} \mathrm{C}$ for sheet and plate material [10] and while this data cannot be directly compared in the plots in Figure 1, it can be utilized in a LM plot. As shown in Figure 2, there is sufficient data to create a LM plot for Alloy 282, if data from material with a single-step and twostep aging treatment are both utilized. The data from Purgert et al. [4] is from annealed material either (1) aged at $1010^{\circ} \mathrm{C}$ for 2 hours plus $788^{\circ} \mathrm{C}$ for 8 hours or (2) only aged at $800^{\circ} \mathrm{C}$ for 4 hours. This data includes two product forms, $100 \mathrm{~mm}$ diameter cast ingot and wrought $14 \mathrm{~mm}$ thick plates [4]. The Haynes international data is from sheet or plate (identified in the plot legend of Figure 2) and the material has received a two-step aging treatment, $1010^{\circ} \mathrm{C}$ for $2 \mathrm{~h}$ plus $788^{\circ} \mathrm{C}$ for 8 hours [10]. The plate data from [10] tends to fall to the right of the LM curve, determined only from sheet data from [10], as does the data points from Purgert et al. [4]. While not as far, the data from Song et al. [8] also falls to the right of the LM curve. 


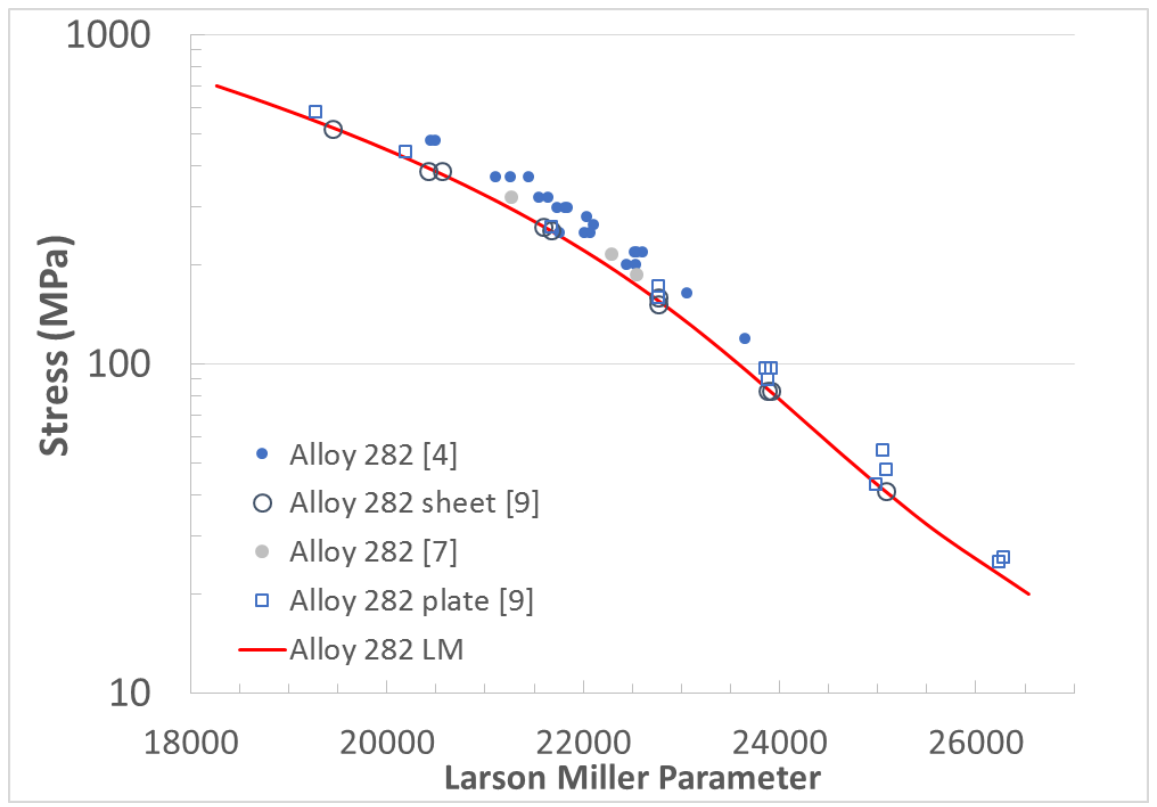

Figure 2 - Alloy 282 Larson-Miller correlation based upon data from [9] plotted with creep data available in references $[4,7,9]$.

The LM parameter, despite likely being an underestimation, was used to calculate the stress to result in a 100,000 h rupture lifetime for Alloy 282, as shown in Figure 3. For comparison, the Alloy 617 [11] and 740/740H [12] LM correlations were also used to calculate the respective stress for a 100,000 hour rupture lifetime for comparison. The $100,000 \mathrm{~h}$ rupture stress is substantially lower in Alloy 617 than Alloy 282 and Alloy $740 / 740 \mathrm{H}$. With the exception of at $800{ }^{\circ} \mathrm{C}$, the calculated stress to result in a 100,000 hour rupture lifetime of Alloy 740/740H was slightly higher than calculated for Alloy 282 . This, however, does not appear consistent with the plots in Figure 1 and is more likely a result of the limited data set utilized to determine the LM curve. For decisions on the alloy down-selection, it is reasonable to consider the creep rupture strength similar for Alloy 282 and Alloy $740 \mathrm{H}$. It is also a possibility that the creep strength of sheet is slightly lower than it is for plate material for Alloy 282. 


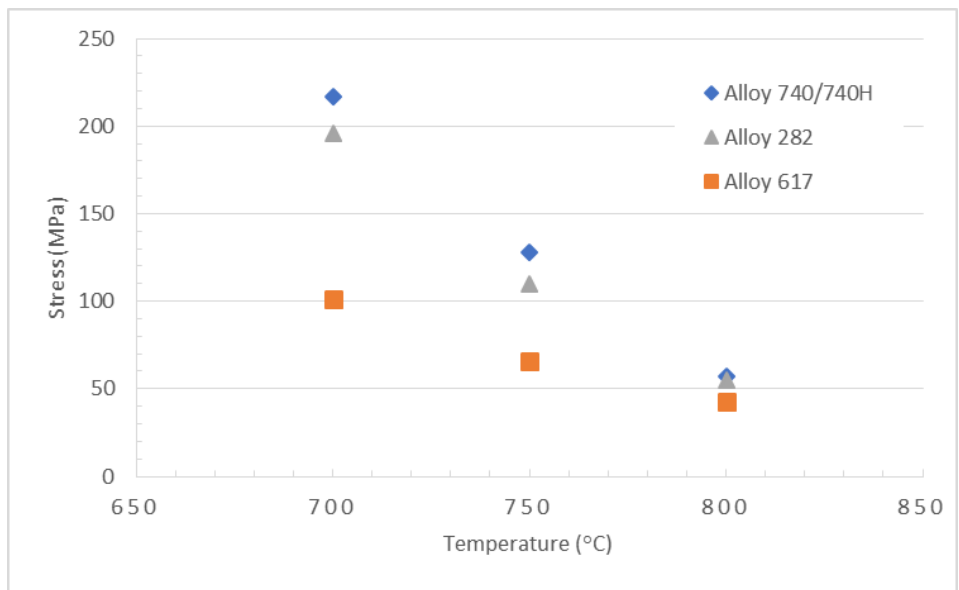

Figure 3 - Approximate stress for a 100,000 h rupture life for Alloys 617 [11], 740/740H [12], and 282 calculated based upon LM curves. The LM curve utilized for Alloy 282 was the one shown in Figure 2.

A quantitative method to differentiate the two alloys was preferred for downselection. One such method used in design is a weighted decision matrix, which ranks multiple design criterion based on degree of importance for a given design to assign weights. It is noted that the design criteria and the estimates of weights impact the outcome of the decision matrix. The criteria and associated weights for a CSP thermal receiver are described in the following paragraphs for a decision matrix including the candidate alloys.

The hierarchical objective tree is depicted in Figure 4. Properties and processing were decided upon as the two second tier criterion and 6 criterion were utilized in the third tier. For the latter, the criteria includes strength at room temperature (RT), strength at $700{ }^{\circ} \mathrm{C}$, strength at $800{ }^{\circ} \mathrm{C}$, weld strength, weldability, and ageing treatment complexity.

The weight estimates assigned to each of the criterion were based on importance for future CSP thermal receiver designs and rated using a 5 point scale, ranging from 0 to 4. These values were then translated into a weight by dividing the importance value by the sum of the total importance values for a given criterion. For example, RT strength was assigned an importance value of 1 , which was then divided by the sum of the properties importance values (strength at $R T$, strength at $700^{\circ} \mathrm{C}$, strength at $800{ }^{\circ} \mathrm{C}$, and weld strength) to calculate the weight (1/12 or 0.08 ). For processing, a weight of 0.25 was assigned and for properties a weight of 0.75 . The weight factor is then calculated by multiplying the weight of the lower level criterion by the higher level criterion or for strength at $R T, 0.08 \times 0.75$ or 0.06 . The values for each criterion are in Table 1 and also shown in the hierarchical objective tree (Figure 4). 
Table 1 - Weighted decision matrix criteria and importance, weight, and weight factor values. This importance values are on a 5 point scale, ranging from 0 to 4 .

\begin{tabular}{|c|c|ccc|}
\hline $\begin{array}{c}\text { Criteria } \\
\text { (Weight) }\end{array}$ & Criteria & Importance & Weight & $\begin{array}{c}\text { Weighting } \\
\text { Factor }\end{array}$ \\
\hline \multirow{4}{*}{$\begin{array}{c}\text { Properties } \\
(0.75)\end{array}$} & Strength at RT & 1 & 0.08 & 0.06 \\
\cline { 2 - 5 } & Strength at $750^{\circ} \mathrm{C}$ & 4 & 0.33 & 0.25 \\
\cline { 2 - 5 } & Strength at $800{ }^{\circ} \mathrm{C}$ & 4 & 0.33 & 0.25 \\
\cline { 2 - 5 } & Weld strength & 3 & 0.25 & 0.19 \\
\hline \multirow{2}{*}{$\begin{array}{c}\text { Processing } \\
(0.25)\end{array}$} & Aging treatment complexity & 2 & 0.5 & 0.13 \\
\cline { 2 - 5 } & Alloy weldability & 2 & 0.5 & 0.13 \\
\hline
\end{tabular}

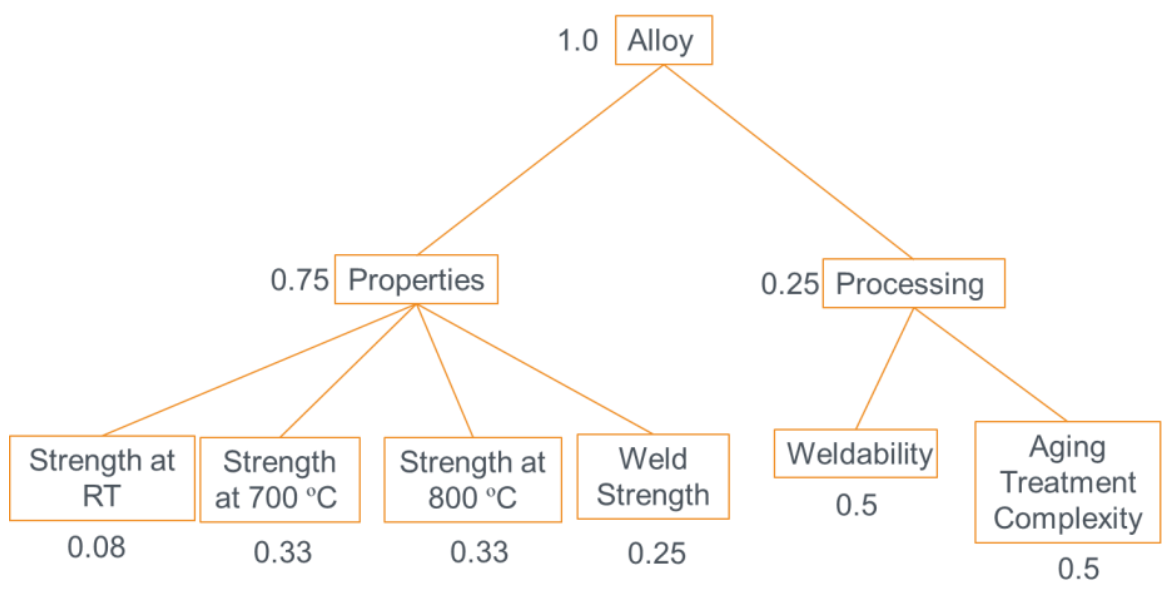

Figure 4 - Hierarchical objective tree with estimated weights for alloy down-selection for developing a creep-fatigue interaction diagram for a candidate CSP thermal receiver alloy.

Scores were then assigned for each alloy for each criterion in a weighted decision matrix, as shown in Table 2. These scores were assigned based on information from a 
A-USC DOE Fossil Energy report [4], the ASME Code [11-13], Haynes International $[10,14,15]$ and Special Metals $[5,16,17]$ alloy brochures, as well as industry input (Brayton Energy, SolarReserve). The weld strength reduction factor is not known for Alloy $X$, but even the highest score of 4 would not change the outcome of the matrix and therefore, it was left blank. Based on this assessment, Alloy 282 and Alloy $740 \mathrm{H}$ have similar total ratings.

Table 2 - Scored weighted decision matrix for an alloy down-selection for development of a creep-fatigue interaction diagram for a CSP thermal receiver candidate alloy.

\begin{tabular}{|c|c|c|c|c|c|c|c|c|c|c|c|c|c|}
\hline \multirow[b]{2}{*}{ Criteria } & \multirow[b]{2}{*}{$\begin{array}{c}\text { Weighting } \\
\text { Factor }\end{array}$} & \multicolumn{2}{|c|}{ Alloy 625} & \multicolumn{2}{|c|}{ Alloy 617} & \multicolumn{2}{|c|}{ Alloy 230} & \multicolumn{2}{|c|}{ Alloy $\mathrm{X}$} & \multicolumn{2}{|c|}{ Alloy $740 \mathrm{H}$} & \multicolumn{2}{|c|}{ Alloy 282} \\
\hline & & Score & Rating & Score & Rating & Score & Rating & Score & Rating & Score & Rating & Score & Rating \\
\hline Strength at RT & 0.06 & 2 & 0.13 & 1 & 0.06 & 3 & 0.19 & 2 & 0.13 & 3 & 0.19 & 3 & 0.19 \\
\hline Strength at $750^{\circ} \mathrm{C}$ & 0.25 & 2 & 0.50 & 2 & 0.50 & 2 & 0.50 & 1 & 0.25 & 3 & 0.75 & 3 & 0.75 \\
\hline Strength at $800^{\circ} \mathrm{C}$ & 0.25 & 2 & 0.50 & 2 & 0.50 & 2 & 0.50 & 2 & 0.50 & 2 & 0.50 & 2 & 0.50 \\
\hline Weld strength reduction factor & 0.19 & 3 & 0.56 & 3 & 0.56 & 2 & 0.38 & & 0.00 & 2 & 0.38 & 4 & 0.75 \\
\hline Complexity of aging treatment & 0.13 & 3 & 0.38 & 4 & 0.50 & 4 & 0.50 & 4 & 0.50 & 3 & 0.38 & 2 & 0.25 \\
\hline Alloy weldability & 0.13 & 3 & 0.38 & 3 & 0.38 & 3 & 0.38 & 3 & 0.38 & 3 & 0.38 & 1 & 0.13 \\
\hline TOTAL & 1.0 & & 2.44 & & 2.50 & & 2.44 & & 1.75 & & 2.56 & & 2.56 \\
\hline
\end{tabular}

Specific differences in the decision matrix of Alloy 282 and Alloy $740 \mathrm{H}$ are the weld strength reduction factor, which is likely near 1 for Alloy 282, whereas it is 0.7 for Alloy $740 \mathrm{H} \mathrm{[4]} \mathrm{as} \mathrm{well} \mathrm{as} \mathrm{the} \mathrm{complexity} \mathrm{of} \mathrm{the} \mathrm{ageing} \mathrm{treatment} \mathrm{and} \mathrm{the} \mathrm{alloy} \mathrm{weldability.} \mathrm{The}$ decision matrix scored Alloy 282 as having a two-step aging treatment, however, it is possible that by the time a CSP design would consider these alloys utilizing the creepfatigue interaction diagram developed as part of this project, the decision will be made to use Alloy 282 with a single-step aging treatment as consider by [4].

In conclusion, the creep strength of Alloy 282 and Alloy $740 \mathrm{H}$ were similar and if all of the available Alloy 282 creep data was utilized there is a sufficient amount to determine a LM curve. The total scores for the weighted decision matrix resulted in Alloy $740 \mathrm{H}$ and Alloy 282 being equal, however, this project will proceed with testing of Alloy $740 \mathrm{H}$ due to several factors. There is some concern over combining creep data for Alloy 282 from different heat treatments, as heat treatment is an important factor in final material properties. Without combining the creep data, however, there is not enough to generate the D-diagram. Alloy $740 \mathrm{H}$ is also more mature than Alloy 282 , referring to the availability of data, as well as the existence of an ASME BPVC code case. While not grounds for selecting Alloy $740 \mathrm{H}$ over Alloy 282 , given the similarities in scores (Table 2), there is a preference to move forward with the alloy that is further developed. Finally, the existence of other Gen3 CSP projects studying Alloy $740 \mathrm{H}$, which were selected from the recent FOA, provide opportunities for collaboration and further development if this project were also to select Alloy $740 \mathrm{H}$.

For Task 1, Milestone 2, the procurement of Alloy $740 \mathrm{H}$ material and machining of test specimens for creep and cyclic testing was delayed until the alloy down-selection was completed. The decision to move forward with developing a creep-fatigue interaction diagram for Alloy $740 \mathrm{H}$ was made towards the end of the second quarter. 
From that point, a plate of Alloy $740 \mathrm{H}$ already available at INL was shipped to Metcut for machining. Nine creep rupture specimens and 16 fatigue/creep-fatigue specimens will be machined from this plate. Specimens are expected back at INL by mid-September, when testing will begin. Plates of Alloy 709 will be ordered so that additional test specimens will be ready when the preliminary testing has finished.

An experimental test matrix for Alloy $740 \mathrm{H}$ was outlined at two temperatures, 750 and $850{ }^{\circ} \mathrm{C}$, and are shown in Table 3 . The total test time is approximately 3 years and, if conducted in 2 test frames, testing could be completed in 1.5 years. The test times are estimated from cycles to failure $\left(\mathrm{N}_{\mathrm{f}}\right)$ estimates from creep-fatigue test results of Alloy $740 \mathrm{H}$ at $700^{\circ} \mathrm{C}[18]$ and Alloy 617 tests at $850^{\circ} \mathrm{C}[19]$.

Prior to initiating the creep-fatigue testing, however, some scoping studies should be completed to assess whether a strain-controlled hold time at peak tensile strain or at peak compressive strain is most detrimental to the creep-fatigue resistance. For selected conditions, tensile-hold creep fatigue testing and compressive-hold creepfatigue testing will first be completed. From these tests, outlined in Table 4, the dwell sensitivity of Alloy $740 \mathrm{H}$ will be determined and this will guide where in the cycle the strain-controlled hold (peak tensile or peak compressive strain) will be for the test matrices in Table 3. If the compressive-hold time tests result in lower numbers of cycles to failure than the associated tensile-hold time tests, then the tests in Table 3 will be conducted with strain-controlled holds at peak compressive strain. The test matrix in Table 4 will introduce an additional 3 to 4 months of cyclic test time.

This determination is particularly important because by volume, receiver tubes primarily experience compressive thermal stresses [20]. For nickel alloy, Alloy 617, Rao et al. found that it was tensile-dwell sensitive at $0.6 \%$ total strain and $950^{\circ} \mathrm{C}$ in impure helium [21]. Carroll et al. observed a similar number of cycles to failure for tensile-only and compressive-only hold times at $0.3 \%$ total strain at $950^{\circ} \mathrm{C}$ in air [22]. It is noted that a test temperature of $950^{\circ} \mathrm{C}$ is significantly higher than planned in this program.

Table 3 - Experimental fatigue and creep-fatigue test matrices for Alloy $740 \mathrm{H}$ at $750{ }^{\circ} \mathrm{C}$ (a) and $850^{\circ} \mathrm{C}$ (b). The continuous-cycle fatigue tests will provide the denominator of the fatigue term to develop a creep-fatigue interaction diagram.

\begin{tabular}{|c|c|c|c|c|}
\hline Strain Range & $\begin{array}{c}\text { Approx. Cycles to } \\
\text { Failure (Nf) }\end{array}$ & Hold Time & Tests & $\begin{array}{c}\text { Approx. } \\
\text { Test Time }\end{array}$ \\
\hline$\%$ & cycles & minutes & & days \\
\hline 0.6 & 60,000 & 0 & 3 & 8 \\
0.6 & 12,500 & 10 & 1 & 89 \\
0.6 & 6,000 & 60 & 1 & 251 \\
0.6 & 3,000 & 120 & 1 & 250 \\
1.0 & 2,000 & 0 & 3 & 1 \\
1.0 & 200 & 60 & 1 & 8 \\
1.0 & 35 & 240 & 1 & 6 \\
\hline
\end{tabular}

(a) 


\begin{tabular}{|c|c|c|c|c|}
\hline Strain Range & $\begin{array}{c}\text { Approx. Cycles to } \\
\text { Failure (Nf) }\end{array}$ & Hold Time & Tests & $\begin{array}{c}\text { Approx. } \\
\text { Test Time }\end{array}$ \\
\hline$\%$ & cycles & minutes & & days \\
\hline 0.4 & 10,000 & 0 & 3 & 1 \\
0.4 & 3,000 & 10 & 1 & 21 \\
0.4 & 2,000 & 60 & 1 & 84 \\
0.4 & 1,000 & 240 & 1 & 167 \\
1.0 & 2,000 & 0 & 3 & 1 \\
1.0 & 1,000 & 10 & 1 & 7 \\
1.0 & 500 & 60 & 1 & 21 \\
1.0 & 200 & 240 & 1 & 33 \\
1.0 & 200 & 600 & 1 & 83 \\
\hline
\end{tabular}

(b)

Table 4 - Experimental creep-fatigue test matrices for Alloy $740 \mathrm{H}$ that will be conducted with a strain-controlled hold at peak tensile strain and a second time with a straincontrolled hold with a compressive strain.

\begin{tabular}{|c|c|c|c|c|}
\hline Temperature & Strain Range & $\begin{array}{c}\text { Approx. Cycles to } \\
\text { Failure (Nf) }\end{array}$ & Hold Time & $\begin{array}{c}\text { Approx. Test } \\
\text { Time }\end{array}$ \\
\hline$\left({ }^{\circ} \mathrm{C}\right)$ & $\%$ & cycles & minutes & days \\
\hline 750 & 0.6 & 12,500 & 10 & 89 \\
750 & 1.0 & 200 & 60 & 8 \\
850 & 0.4 & 3,000 & 10 & 21 \\
850 & 1.0 & 500 & 60 & 21 \\
\hline
\end{tabular}

To compliment Alloy $740 \mathrm{H}$ creep data currently available and ensure the procured Alloy $740 \mathrm{H}$ material has similar creep resistance, two confirmatory, short term (less than $10,000 \mathrm{~h}$ ) creep tests will be conducted at 700 and $750^{\circ} \mathrm{C}$. These tests will also allow for ratcheting provisions up to $750^{\circ} \mathrm{C}$. In order to extend ratcheting provisions to $850^{\circ} \mathrm{C}$, seven additional creep tests at each temperature $\left(800\right.$ and $\left.850^{\circ} \mathrm{C}\right)$ are required beyond those currently available in the literature. For each temperature, these tests include one long-term test (approximately 10,000 h) and three shorter-term tests (less than 10,000 h). Each short-term test will be repeated twice to give some indication of the expected in-batch variation of the material creep response. Time will not allow for replicate testing of the long term tests. A suggested test matrix is shown in Table 5. 
Table 5 - Suggested experimental creep test matrices for Alloy $740 \mathrm{H}$, including confirmatory tests at 700 and $750^{\circ} \mathrm{C}$, as well as additional testing need to extend ratcheting provisions.

\begin{tabular}{lll}
\hline $\begin{array}{l}\text { Temperature } \\
(\text { 으 })\end{array}$ & $\begin{array}{l}\text { Applied stress } \\
(\mathrm{MPa})\end{array}$ & $\begin{array}{l}\text { Approximate rupture life } \\
(\mathrm{h})\end{array}$ \\
\hline 700 & 340 & 5200 \\
700 & 390 & 1900 \\
750 & 265 & 1900 \\
750 & 220 & 6000 \\
800 & 115 & 11000 \\
800 & 140 & 4700 \\
800 & 160 & 2500 \\
800 & 200 & 800 \\
850 & 50 & 10800 \\
850 & 70 & 4900 \\
850 & 80 & 3300 \\
850 & 100 & 1600 \\
\hline
\end{tabular}

\section{Task 2}

This section describes a reference thermomechanical model of a tubular CSP receiver. The goal of this reference model is not to actually design a receiver, but rather to serve as a realistic test bed to assess different potential creep-fatigue and ratcheting design methods. As such, the goal is to be realistic but not to perfectly match any particular design details.

For the reference model we consider a $360^{\circ}$ external cylindrical receiver with $8.5 \mathrm{~m}$ diameter and $10.5 \mathrm{~m}$ in length is considered. Thermal and structural analysis of the receiver tubes are performed under the radiation heat flux map on the day of spring equinox. A computer code, called DELSOL3 [33], developed by Sandia National Laboratory is used to calculate the radiation heat flux map on the receiver. At first, an optimization calculation is run on DELSOL3 to determine the best combination of the tower height, receiver size, field layout, heliostat spacing, and tower position at electrical design power level of $45 \mathrm{MWe}$ (and thermal power of $120 \mathrm{MWe}$ ) and flux limit of 1.2 $\mathrm{MW} / \mathrm{m}^{2}$. Once the system is optimized, the heat flux map on the receiver at different times of the day are determined. Figure 5 shows the radiation heat flux map at noon on the day of spring equinox for an optimal solar receiver system. 1D smart aiming at the centerline of the receiver has been employed to determine the heat flux. As seen in the figure, radiation solar heat flux is maximum in the north hemisphere and minimum in the south hemisphere. As the heat flux is symmetric about north-south axis, two flow paths 
each containing 9 panels are considered. Salt enters the receiver at the north side through panel- 1 and leaves the receiver at the south side from panel-9 (Figure-6). Each panel consists of 32 vertical tubes with $4.22 \mathrm{~cm}$ in outer diameter and $1.65 \mathrm{~mm}$ in

thickness. The tube pitch is considered as 1.08 times the outer diameter. Note that, this initial design configuration of the tubes is based on the findings in [34].

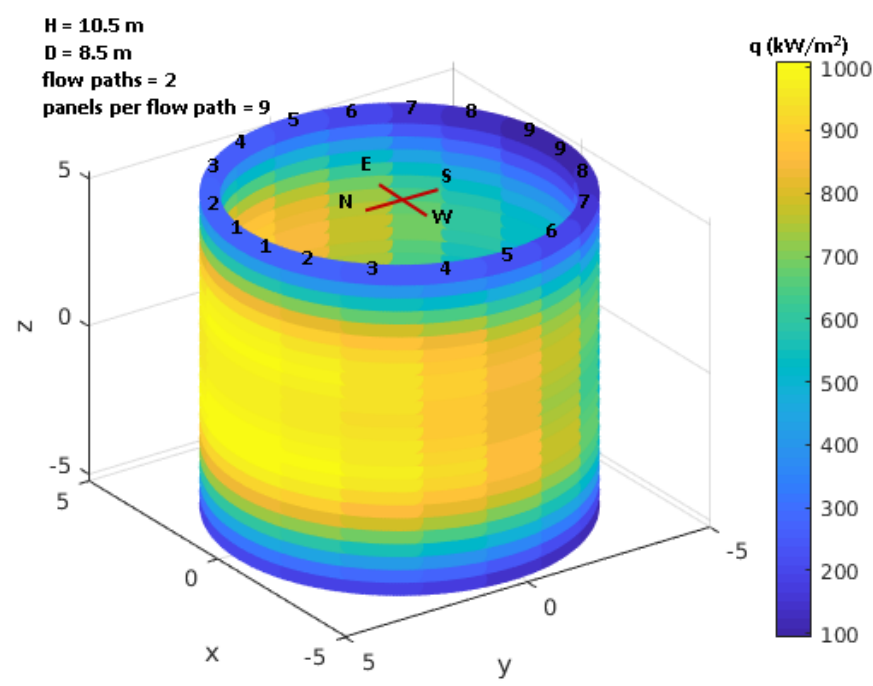

Figure 5: Heat flux distribution on the external receiver at noon on the day of spring equinox. 


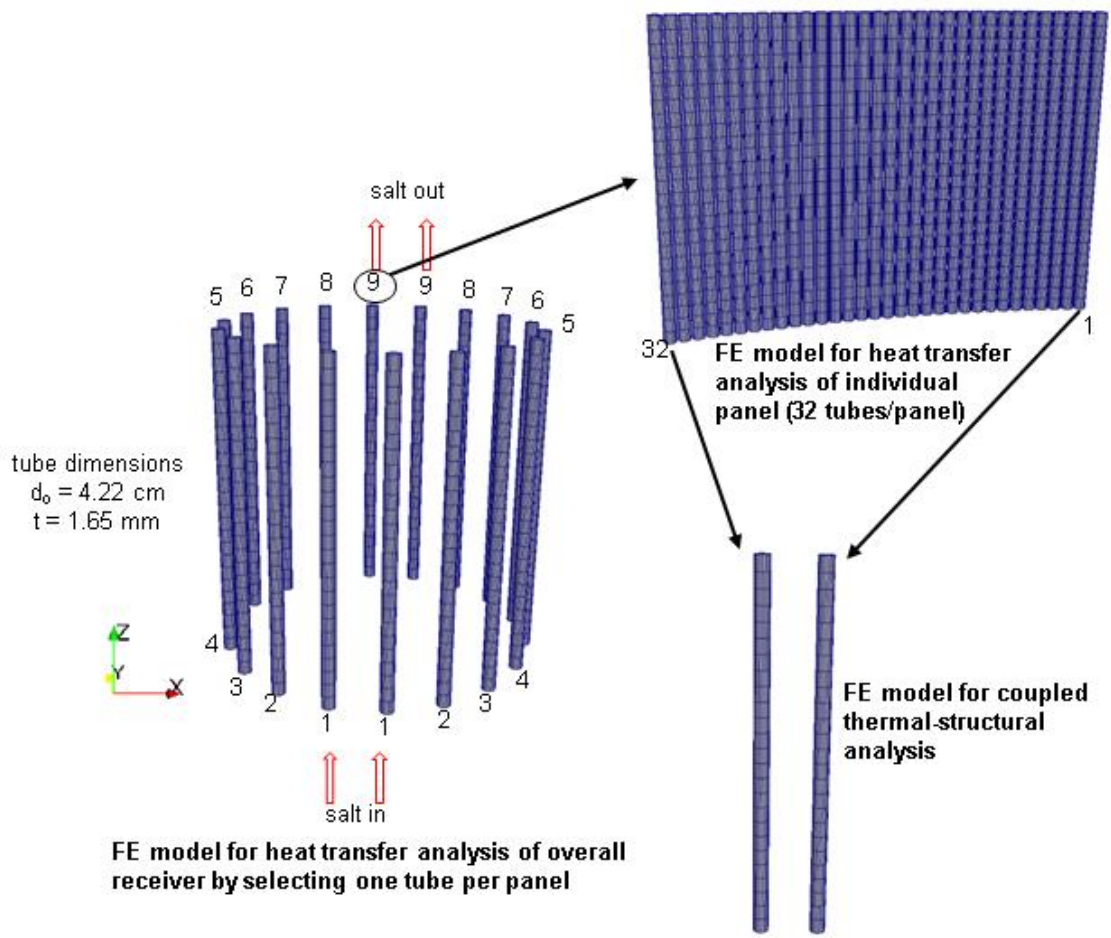

Figure 6: Finite element models for thermal and structural analysis of receiver tubes.

Thermal and structural analysis of the receiver tubes are performed in 3 steps. First, heat transfer analysis of the whole receiver is done by considering one tube per panel. A panel with maximum tube temperature is then selected for heat transfer analysis of all 32 tubes in that panel. In the last step, a coupled thermal-structural analysis is performed by considering 2 tubes at two extreme ends of that panel. Figure 6 shows all the FE models for thermal and structural analyses. A chloride salt with constant inlet and maximum outlet temperatures of $290^{\circ} \mathrm{C}$ and $605^{\circ} \mathrm{C}$, respectively, is considered. Salt temperature is assumed to vary linearly along the flow path. The convective heat transfer coefficient is $6154 \mathrm{~W} / \mathrm{m}^{2}-\mathrm{K}$ considering a constant salt mass flow rate (for overall receiver) of $286 \mathrm{~kg} / \mathrm{s}$. During thermal simulation, half of the outer tube wall that faces heliostats is considered as heating surface as well as for convective and radiative heat loss to the environment, while the other half is considered as adiabatic surface. For structural simulation of the 2 selected tubes, fixed displacement boundary condition is employed for bottom surface, while nodes on the top surface are fixed in $x$ - and $y$ direction but can move equally in z-direction. Temperature dependent material properties for this example calculation are given in Table 6. 
Table 6: Temperature dependent material properties for alloy $740 \mathrm{H}$.

\begin{tabular}{|c|c|c|c|c|c|c|}
\hline & $\begin{array}{l}23 \\
{ }^{\circ} \mathrm{C}\end{array}$ & $\begin{array}{l}200 \\
{ }^{\circ} \mathrm{C}\end{array}$ & $\begin{array}{l}400 \\
{ }^{\circ} \mathrm{C}\end{array}$ & $\begin{array}{l}600 \\
{ }^{\circ} \mathrm{C}\end{array}$ & $\begin{array}{l}700 \\
{ }^{7} \mathrm{C} \\
\end{array}$ & $\begin{array}{c}800 \\
{ }^{8} \mathrm{C}\end{array}$ \\
\hline Thermal conductivity, $\mathrm{k}(\mathrm{W} / \mathrm{m}-\mathrm{K})$ & 10.2 & 13 & 15.7 & 18.4 & 20.2 & 22.1 \\
\hline $\begin{array}{l}\text { Coefficient thermal expansion, } \alpha \\
(\mu \mathrm{m} / \mathrm{m}-\mathrm{K})\end{array}$ & & 13.04 & 13.93 & 14.57 & 15.03 & 15.72 \\
\hline $\begin{array}{l}\text { Elastic modulus, E (GPa) } \\
\text { Yield stress, } \sigma^{y}(\mathrm{MPa})\end{array}$ & $\begin{array}{l}221 \\
724\end{array}$ & 212 & 200 & 186 & $\begin{array}{l}178 \\
567\end{array}$ & $\begin{array}{l}169 \\
547\end{array}$ \\
\hline
\end{tabular}

Figure 7 represents the evolution of external and internal wall temperature of the tubes in the whole representative receiver considering one tube per panel. The temperature contour plots are shown for radiation heat flux at noon and at $4 \mathrm{pm}$ on the day of spring equinox. Temperature in tubes is found to vary not only in radial and longitudinal direction but also along the circumference. Tube in panel- 9 is found to be hotter than tubes in other panels and therefore panel- 9 is considered for further analysis. 

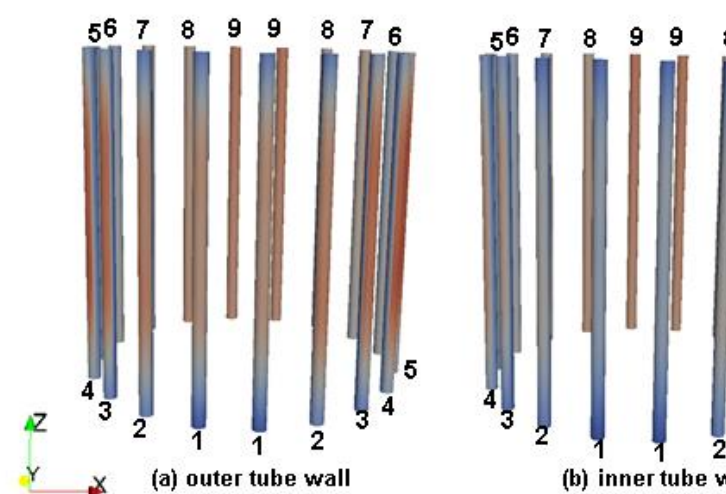

(b) inner tube wal

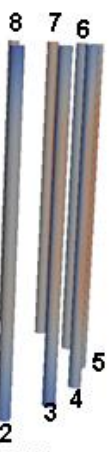

Temperature $\left({ }^{\circ} \mathrm{C}\right)$
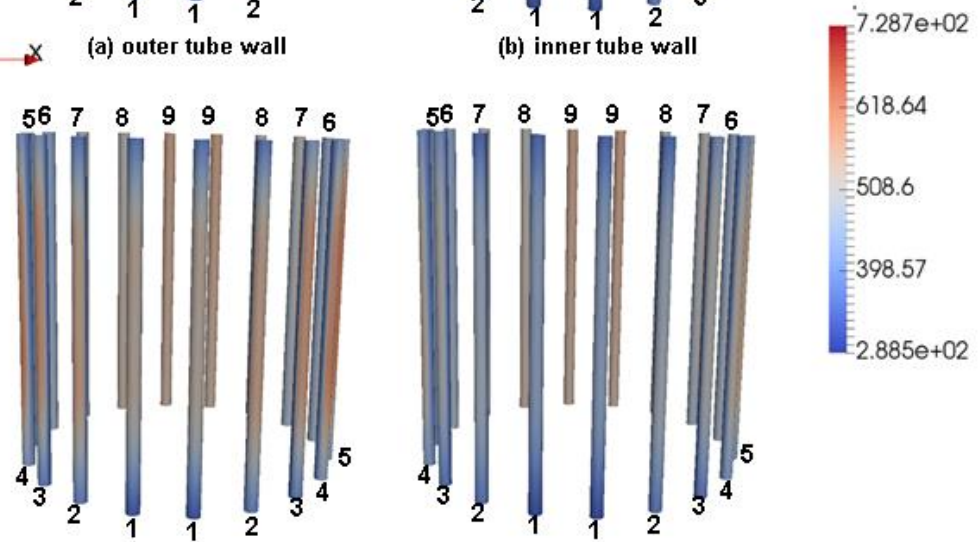

(c) outer tube wall

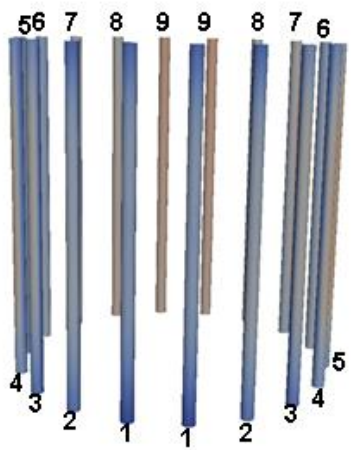

(d) inner tube wall
Formatted: Font: (Default) Arial

Formatted: Font: (Default) Arial, $12 \mathrm{pt}$

Figure 7: Temperature evolution in the representative receiver at noon $(a, b)$ and at $4 \mathrm{pm}$ (c, d) on the day of spring equinox.

The temperature variation in outer tube wall is shown in Figure 8. As seen, there is a significant variation in temperatures between the heating surface and the adiabatic surface. A comparison in maximum tube temperatures shows that tube 32 is the hottest while tube 1 is the coldest in panel-9. This is because tube 32 receives the highest radiation heat flux while tube 1 receives the lowest and the salt temperature profile does not vary among tubes in a panel. Due to having two extreme temperature profiles, tubes 1 and 9 are considered for the coupled thermal-structural simulation. 

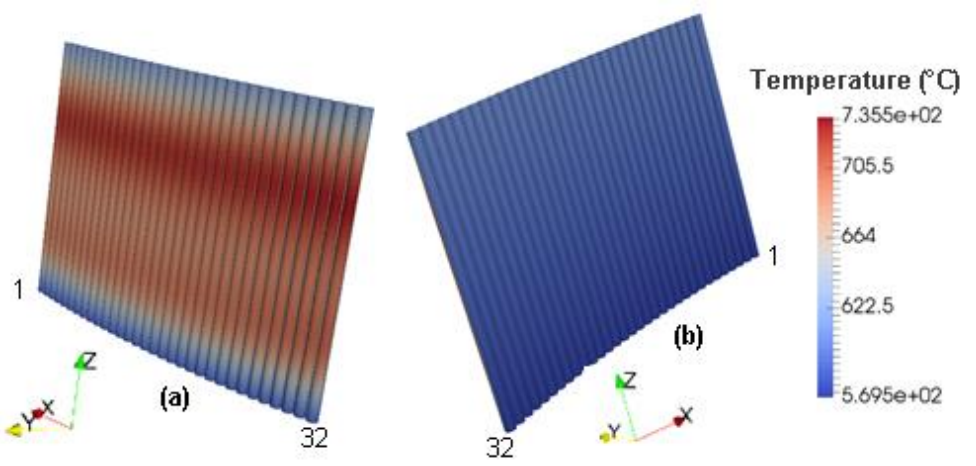

Figure 8: Outer wall temperature distribution in 32 tubes of panel-9. (a) heating surface facing heliostats (b) adiabatic surface not facing heliostats.

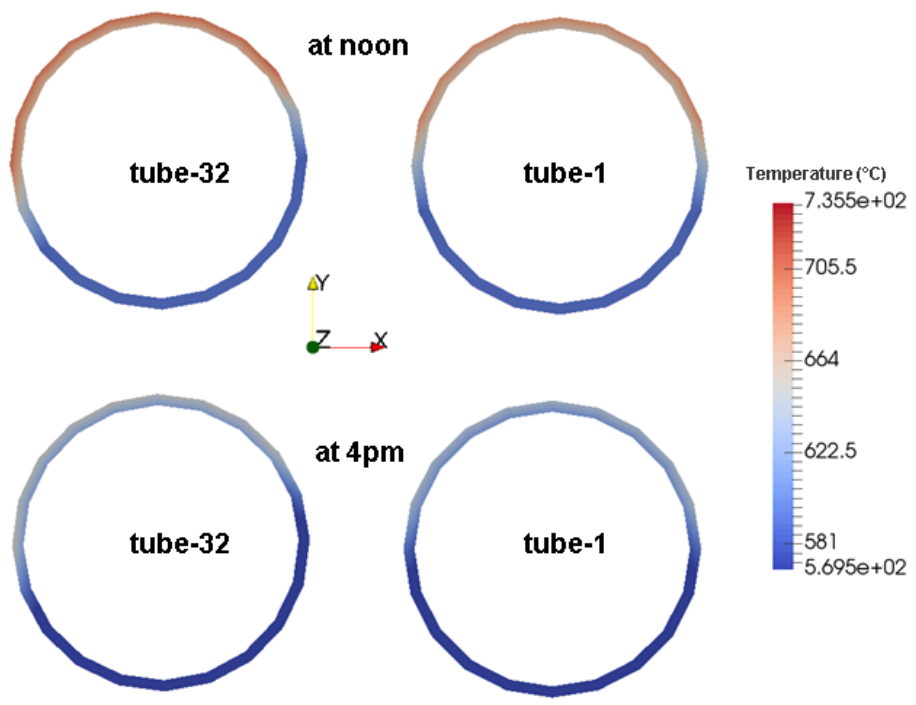

Figure 9: Radial and circumferential variation of temperature in tubes 1 and 32 of panel9 at $z=2.1 \mathrm{~m}$. (a) at noon and (b) at $4 \mathrm{pm}$ on the day of spring equinox.

A better representation of the temperature variation across tube thickness and along the circumference can be seen in Figure 9 which shows the temperature contour plots of tube cross-sections at $z-2.1 \mathrm{~m}$ for tubes 1 and 32 in panel-9. The two tube models are simulated for 50 hours- every 10 hours representing the radiation heat flux map for the whole day of spring equinox. Figure 10 compares the cyclic variation of maximum inner and outer wall temperatures for both the tubes. The difference in maximum temperature 
between outer wall and inner wall is around $50^{\circ} \mathrm{C}$ while it is $15^{\circ} \mathrm{C}$ between two tubes.

The von Mises stress distribution at noon is shown in Figure 11. The figure also

presents the cycle by cycle variation of the maximum von Mises stress for both tubes.

The maximum von Mises stress in tube 32 is found to be $315 \mathrm{MPa}$ while it is $309 \mathrm{MPa}$ in tube 1.
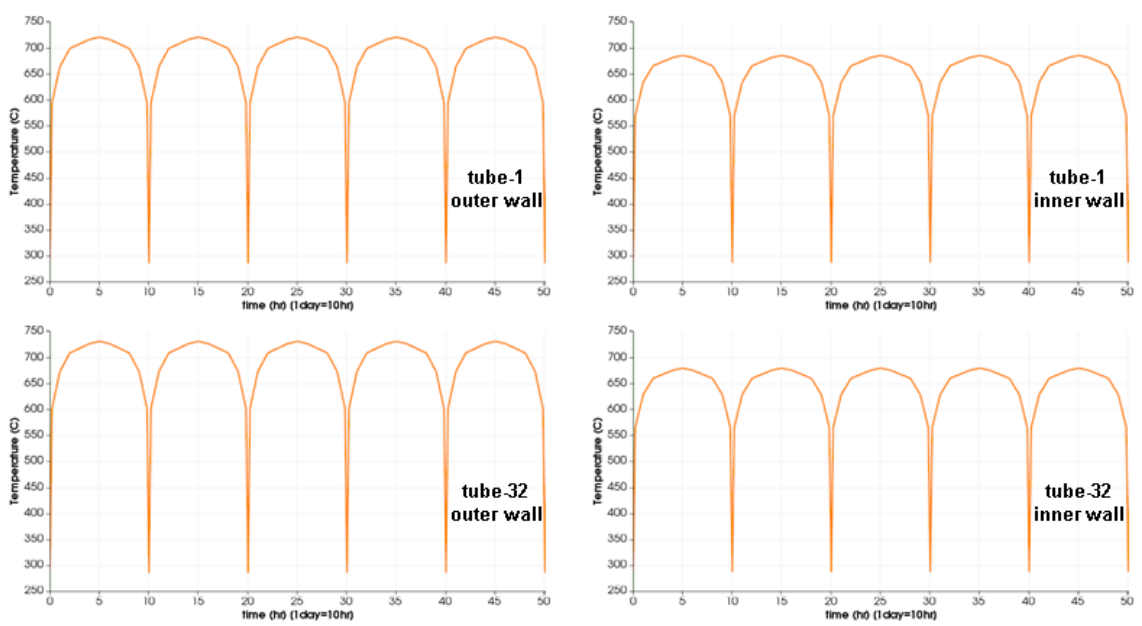

Figure 10: Maximum outer and inner wall temperatures in tubes 1 and 32 of panel-9 under spring equinox day heat flux cycles. 

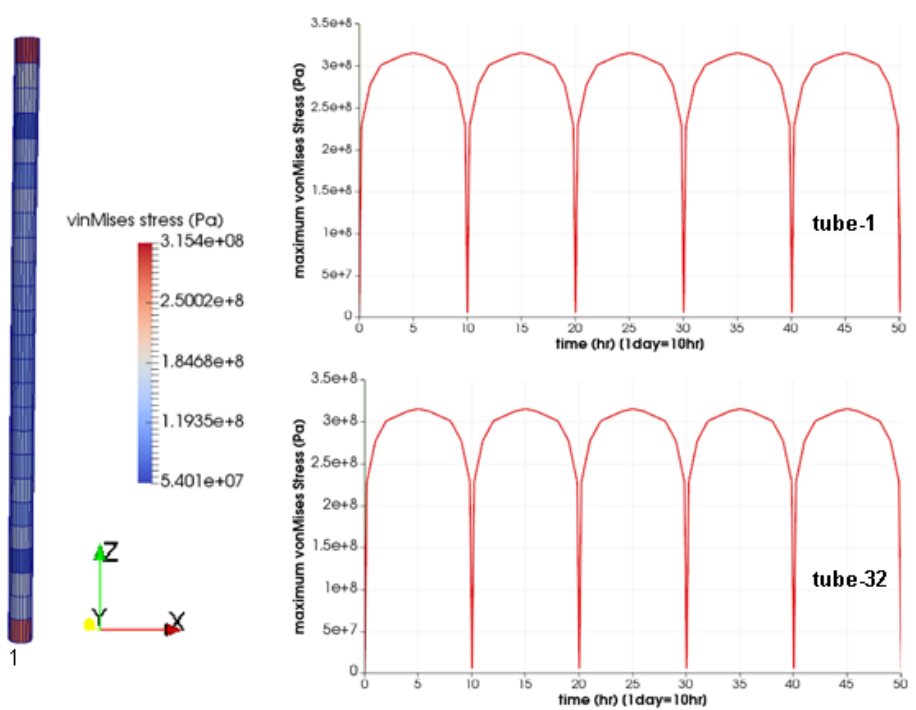

Figure 11: (a) Contour maps of the von Mises stress at noon on the day of spring equinox in tubes 1 and 32 of panel-9. (b) Maximum von Mises stress in tubes under spring equinox day heat flux cycles.

Some improvements to this model will be made before running the design method assessment simulations, described above. First, the mechanical fixity of the tubes on the top and bottom connections to the pipe manifold will be relaxed, reflecting the approximately-equal thermal expansion of the tubes and the manifold. Secondly, a more complete insolution history will be consider, including seasonal, day-night, and daily variations. Finally, the salt inflow and outflow temperatures will be increased to reflect the higher temperatures expected in newer molten salt and $\mathrm{sCO}_{2}$ designs. We expect to operate with a peak noon-summer-solstice wall temperature of approximately $800^{\circ} \mathrm{C}$.

\section{Task 3}

As proposed, the focus of Task 3 was an assessment of the environmental interaction during creep-fatigue of a candidate structural material. Specifically, a preliminary assessment of the potential influence of an operating environment, such as argon or helium, has on the creep-fatigue resistance. While the capability exists to perform cyclic testing in specialized environments such as oxidizing and decarburizing helium or argon at INL, there are testing limitations on carburizing environments. Gas phase CSP solar thermal receivers may operate in a $\mathrm{SCO}_{2}$ environment and thus carburizing environments are of interest. However, cyclic testing in carburizing environments is not possible at Idaho National Laboratory because of the possibility of 
carbon depositing on frame components and the extensometry in the cyclic test chamber. Test specimens could have static pre-exposures in a carburizing environment in order to develop a representative microstructure and then subjected to cyclic testing. The static exposures and testing would be conducted at ambient pressures, not higher pressures such as those expected in $\mathrm{SCO}_{2}$ gas phase CSP. Differences due to pressure could possibly be minimized by pre-exposing the cyclic test specimens to achieve a specified microstructure that was deemed representative based on previous studies focused on the influence of pressure on nickel-base alloys in $\mathrm{CO}_{2}$ environments.

In consideration of the optimal way to move forward with Task 3 , given cyclic testing limitations and challenges, several key questions are important to have answered. The first is whether a 1 bar $\mathrm{CO}_{2}$ environment is representative of a higher pressure $\mathrm{sCO}_{2}$ environment and, if not, what differences are the expected. Secondly, do the candidate nickel-base alloys carburize in a $\mathrm{CO}_{2}$ environment and finally, is cyclic testing of preexposed test specimens representative of cycling in environment.

To answer these questions an extensive literature review has been completed and is summarized in the following paragraphs. To assess whether a 1 bar and higher pressure $\mathrm{CO}_{2}$ environment are similar in terms of the resulting microstructures developed in nickel alloys, several studies of static exposures in a $\mathrm{SCO}_{2}$ environment have been completed. These short-term (500 hours) studies have consistently found that there is minimal influence of $\mathrm{CO}_{2}$ pressure based on static exposures at 125 [23], 200 [24], and 300 [23] bar in comparison to 1 bar at 700 [24] and $750^{\circ} \mathrm{C}[23,24]$. These short-term analyses have encompassed multiple nickel alloys including Alloys 625 [20], 617 [23], 230 [23,24], 740 [23,24], and 282 [23,24]. It was found that mass gains and microstructures of higher pressures specimens were similar to those of 1 bar specimen $[23,24]$, however, a greater depth of Cr depletion occurred at higher pressure for Alloy $282[23,24]$. There were also slightly higher mass gains at 200 bar, particularly in Alloy 740 and 282 [24]. Stressed exposures may differ from static ones. Deformation and cycling will crack grain boundaries that will then oxidize, providing a path for carbon to reach the underlying alloy, as carbon diffuses along oxidized grain boundaries. Pint et al. [23] indicate that creep testing in a $\mathrm{CO}_{2}$ environment is planned. This study will provide key information to begin understanding the influence of environment on mechanical properties.

In terms of the second key question, do candidate nickel alloys carburize in $\mathrm{CO}_{2}$ environment, there has been minimal or no carburization observed in static exposures in four relevant studies at both 1 bar and higher pressures. In one study, Hastelloy C276 was exposed to flowing $\mathrm{sCO}_{2}$ at $20 \mathrm{MPa}$ at both 650 and $750{ }^{\circ} \mathrm{C}$ and very little carburization was observed after 1000 hours [25]. Similarly, a 500 hour static exposures of Alloy $740 \mathrm{H}$ at 1 bar and another at 300 bar $\mathrm{CO}_{2}$ at $750{ }^{\circ} \mathrm{C}$ revealed no internal carburization [23]. Further, in a study of multiple alloys, Alloys 625,282 , and $740 \mathrm{H}$, in 1 bar of $\mathrm{CO}_{2}$ at $750^{\circ} \mathrm{C}$ for 1000 hours minimal or no internal carburization was observed through SEM [25]. It was noted that the oxide was thicker after $1000 \mathrm{~h}$ when cycled every 500 hours versus when cycled every 10 hours and that there was a $\gamma^{\prime}$ depletion zone present in Alloy $740 \mathrm{H}$ and 282 [25]. Finally, PE-16, Alloy 230 and 625 exposed at $650{ }^{\circ} \mathrm{C}$ and $20 \mathrm{MPa}$ in $\mathrm{sCO}_{2}$ also showed no evidence of carburizing [26]. It is noted that all of the available literature data is on short-term studies of static exposures. 
The third question is whether the results would vary in a dynamic environment with deformation and/or cycling. Unfortunately, the literature does not yet answer this question at temperatures in the range of 700 to $850^{\circ} \mathrm{C}$, but it is known that low cycle fatigue and creep-fatigue deformation introduce grain boundary cracks and these cracks often occur early during cycling. The cracks may then oxidize and provide paths for carbon diffusion. It is also possible that the effects of carburization may require longer test times in a dynamic testing environment. Unfortunately, cyclic testing of pre-exposed static test specimens may not provide cracked, oxidized grain boundaries when exposed to a $\mathrm{CO}_{2}$ environment. Therefore, a certain difficulty exists in cyclic testing of nickel alloys in a $\mathrm{CO}_{2}$ environment. The results of creep testing in this environment will provide more information and enable a future decision on the best path forward.

In the meantime, it is recommended that the focus of Task 3 shift to creep and possible cyclic testing of sheet material and/or tubular specimens. CSP receiver designs may use all three product forms, tube, sheet, and foil, thus for a design method to account for all three product forms an understanding of the influence of various thicknesses on fatigue and creep-fatigue is important. There is ample evidence in the literature, described in the following text, that the fatigue behavior of hollow or tubular specimens is reduced relative to that of solid, cylindrical specimens. A lower number of cycles to failure of hollow/tubular specimens (relative to solid, cylindrical) in multiple studies on alloys ranging from structural steels [27-29] to stainless steel [30,31] to Alloy 800 [30] to an aluminum alloy [32]. There was an exception observed for a stainless steel specimen with a $4 \mathrm{~mm}$ thick wall at a lower strain range [31]. Further, this fatigue life detriment was observed to increases with decreasing specimen wall thickness [29], attributed to crack growth rates decreasing with increase in wall thickness [29] due to differences in internal plastic strain [31]. To the authors' knowledge, the influence of tubular specimens on the creep-fatigue (CF) behavior and cycles to failure is not reported.

Based on the literature, fatigue, and possibly creep-fatigue, testing of CSP candidate nickel alloys is likely to show a significant reduction in the cycles to failure for hollow/tubular specimens. For creep-fatigue, this is most likely for fatigue-dominated creep-fatigue tests, those at higher strain ranges and lower temperatures (conditions included in this program in Table 3). The challenging aspect, however, is that the results will likely be dependent on the specimen wall thickness, therefore cyclic testing of sheet of multiple thicknesses will be necessary to enable a description of the debit in cycle life for a given wall thickness. Cyclic testing of sheet and hollow/tubular specimens is more difficult than solid, cylindrical specimens, specifically in regards to buckling in compression.

Based on the importance of the design method encompassing multiple product forms, the Task 3 work scope will shift to include testing of tubular specimens in an effort coordinated with the EPRI project lead by J. Shingledecker. It is foreseen that selected conditions from the creep-fatigue test matrix in Table 3 will be duplicated on Alloy $740 \mathrm{H}$ tube and/or sheet. Further, as part of this task, creep and fatigue testing of sheet stock of varying thickness will be conducted in order to quantify the effect of thickness and provide a comparison for plate. These results will provide the necessary information for design correlations accounting for product form and thickness in 
modified fatigue curves and a modified creep-rupture correlation. In addition, it will also indicate whether the creep-fatigue interaction is influenced by these product forms.

\section{Update on the State of the Art:}

The significance of this project is in delivering (1) a description of the creep-fatigue behavior of a candidate alloy at conditions applicable for a solar thermal receiver and (2) a set of proposed design rules that provide a more accurate assessment of creepfatigue damage in solar thermal receivers. This will include a preliminary recommendation of a creep-fatigue interaction diagram (D-diagram) based upon an assessment of the materials' creep-fatigue response at temperatures of 750 and 850 ${ }^{\circ} \mathrm{C}$. It will also assess the influence of product form and sheet thickness on creep and fatigue properties.

As mentioned previously, aligning the experimental testing program to approximate the expected failure modes for the solar thermal receiver in-service is important. In addition to developing a design method that takes all potential product forms into consideration, the analysis will also encompass anticipated components failure modes. Specifically, consideration of the dwell sensitivity of Alloy $740 \mathrm{H}$ is necessary. Initially, Alloy 617 was considered but as it is primarily solid solution strengthened its primary strengthening mechanism differs from Alloy $740 \mathrm{H}$. As a result, this quarters report recommends an experimental testing program on Alloy $740 \mathrm{H}$ to determine whether tensile or compressive strain-controlled holds are more damaging to the creep-fatigue resistance. Unfortunately, there is not currently data available in the literature regarding the dwell sensitivity of Alloy $740 \mathrm{H}$.

[1] D.K. Fork, J. Fitch, S. Ziaei, R.I. Jetter, J. Solar Ener. Engin. 134 (2012).

[2] J. Ortega, S. Khivsara, J. Christian, C. Ho, P. Dutta, Applied Thermal Engin. 109 (2016) 979-987.

[3] J. Shingledecker, R. Purgert, P. Rawls, Adv. Mater. Tech. Fossil Power Plants Proc. October 22-25, 2013, Waikoloa, Hawaii.

[4] R. Purgert et al. Boiler Materials for Ultra Supercritical Coal Power Plants Final Technical Report for DOE Award DE-FG26-01NT41175., Dec. 2015.

[5] Special Metals, http://www.specialmetals.com/assets/smc/documents/alloys/inconel/inconel-alloy740-h.pdf

[6] J.P. Shingledecker, Metallurgical Effects of Long-Term Stress Rupture in a New Nickel-Base Alloy, Doctoral Dissertation, U. Tennessee, Knoxville, May, 2012.

[7] C.J. Boehlert, S.C. Longanbach, Mater. Sci. Engin. A 528 (2011) 4888-4898.

[8] X. Song, L. Tang, Z. Chen, R. Zhou, J. Mater. Sci. 52 (2017) 4587-4598.

[9] P.J. Maziasz, et al., Adv. Mater. Tech. Fossil Power Plants Proc. $8^{\text {th }}$ Inter. Conf. Oct. 11-14, 2016, Albufcira, Algarve, Portugal.

[10] Haynes International, http://haynesintl.com/docs/default-source/pdfs/new-alloybrochures/high-temperature-alloys/brochures/282-brochure. pdf?sfvrsn=20 
[11] ASME International, ASME Boiler and Pressure Vessel Code, Draft Section III Div 5 Alloy 617 Code Case, In Progress.

[12] ASME International, ASME Boiler and Pressure Vessel Code, Code Case 2702-3 Ni-25Cr-20Co Material Section I, 2017.

[13] ASME Boiler and Pressure Vessel Code, American Society of Mechanical Engineers, 2017.

[14] Haynes International, http://haynesintl.com/docs/default-source/pdfs/new-alloybrochures/high-temperature-alloys/brochures/230-brochure.pdf

[15] Haynes International, http://haynesintl.com/docs/default-source/pdfs/new-alloybrochures/high-temperature-alloys/brochures/x-brochure.pdf?sfvrsn=8

[16] Special Metals, http://www.specialmetals.com/assets/smc/documents/alloys/inconel/inconel-alloy617.pdf

[17] Special Metals, http://www.specialmetals.com/assets/smc/documents/alloys/inconel/inconel-alloy625.pdf

[18] S. Zhang, Y. Takahashi, Adv. Mater. Tech. Fossil Power Plants Proc., Albufeira, Algarve, Portugal (2016).

[19] J.K. Wright et al., Proc. of the ASME 2016 Press. Vessels Piping Con. PVP201663704 July 17-21, 2016, Vancouver, British Columbia, Canada.

[20] I. Berman et al., An Interim Structural Design Standard for Solar Energy Applications, Sandia National Laboratories, 1979.

[21] K.B.S. Rao, H.P. Meurer, H. Schuster, Mater. Sci. Engin. A 104 (1988) 37-51.

[22] M.C. Carroll, L.C. Carroll, Metall. Mater. Trans. A 44 (2013) 3592-3607.

[23] B.A. Pint, R.G. Brese, J.R. Keiser, Materials and Corrosion 68 (2017) 151-158.

[24] B.A. Pint, J.R. Keiser, JOM 67 (2015) 2615-2620.

[25] R.I. Olivares, D.J. Young, P. Marvig, W. Stein, Oxid. Met. 84 (2015) 585-606.

[26] V. Firouzdor, K. Sridharan, G. Cao, M. Anderson, T.R. Allen, Corros. Sci. 69 (2013) 281-291.

[27] G. Shatil, D.J. Smith, E.G. Ellison, Fatigue Fract. Eng. Mater. Struct. 17 (1994) 159170.

[28] Shatil, G., Smith, D.J., Ellison, E.G., Fatigue Fract. Eng. Mater. Struct. 18 (1995) 235-245.

[29] S. Sivaprasad, H.N. Bar, S.K. Gupta, P. Arora, V. Bhasin, Inter. J. Fatigue 61 (2014) 76-86.

[30] J.A. Van Den Avyle, Scripta Metal. 17 (1983) 737-740.

[31] K. Bae, S. Lee, Mater. High Temps. 28 (2011) 33-39.

[32] E.G. Ellison, J.M.H Andrews, J. Strain Anal. 8(3) (1973) 209-219.

[33] Kistler, B. L. A user's manual for DELSOL3: a computer code for calculating the optical performance and optimal system design for solar thermal central receiver plants. Sandia National Laboratories, Sandia Report No. SAND86-8018 (1986).

[34] Rodríguez-Sánchez, M. R., Soria-Verdugo, A., Almendros-lbáñez, J. A., Acosta Iborra, A., \& Santana, D. Thermal design guidelines of solar power towers. Applied Thermal Engineering, 63(1), (2014) 428-438. 